\title{
Stigmatisation of psychiatric disorder
}

\author{
Stephen M. Lawrie
}

Stigmatisation is the process of marking individuals out for community sanction on the basis of some unacceptable deviation from the norm (Goffman, 1963). The stigma of psychiatric disorders and discrimination against psychiatric patients are arguably the greatest remaining barriers to improving the quality of life of sufferers (Sartorius, 1998). I will describe the main effects of such stigmatisation, attempt to identify the main causes and, most importantly. examine what can be done about them.

\section{Manifestations}

Patients with psychiatric disorders often encounter difficulties in obtaining housing, insurance and employment (Read \& Baker, 1996; Hayward \& Bright, 1997). Relatives and friends may drift away, accentuating social isolation. Numerous studies suggest that members of the general population may accept psychiatric patients socially, but tend to withdraw from more personal relationships such as working or living together (Rabkin, 1974; Bhugra, 1989). Social avoidance probably varies with diagnosis (further details available from the author upon request), increases when acute symptoms are evident (Penn et al, 1994) and is most marked (and least likely to change) with those who have been in-patients (Rabkin, 1974).

Worse yet, psychiatric patients also have problems obtaining adequate health services. National Health Service psychiatry is disproportionately underfunded. Patients are often reluctant to present for psychiatric help, which probably worsens prognosis through treatment delay and non-adherence. This is partly because patients feel that they are treated unfairly by the health services, including their own family doctors (Read \& Baker, 1996). In a small study, we found that in-patients with psychosis complained of more stigmatisation by doctors than any other social group (further details available from author upon request). Our recent studies of attitudes in the general population and among general practitioners (Lawrie et al, 1996) also suggest that doctors stigmatise psychiatric patients more than the general public do.
We should appreciate that psychiatrists also stigmatise psychiatric disorder. Everyday examples include: calling someone 'a schizophrenic' rather than 'someone with schizophrenia'; laughing at the more bizarre things some patients say or do; denigrating our patients for not getting better; and advising trainees with psychiatric illnesses to seek another 'less stressful' speciality. One could even argue that having separate legislation for 'mental illness' is discriminatory.

\section{Likely causes}

Patients with psychiatric (and other) disorders have been stigmatised for at least 2000 years (Rosen, 1968; Fabrega, 1990). Stigmatisation. contrary to what some have said (e.g. Scheff, 1966), is a lot more than just 'labelling'. Attitudes are rarely without any foundation and do not have a life of their own. Discrimination against those with infectious illnesses in the past probably had a social survival value and the same may have been true of psychiatric disorder in the pre-treatment era. Employers and insurers may discriminate against patients with a history of psychiatric disorder because of realistic and legitimate concerns about absences from work. The issue is, however, whether such issues influence them more than in comparable medical illnesses and whether the role of treatment is adequately considered.

Stereotypes of 'insanity' are probably learned in childhood and continually reaffirmed, often inadvertently, in ordinary social interactions (Scheff, 1966). Common attitudes include regarding psychiatric illnesses as frightening, shameful, imaginary, feigned and incurable: while psychiatric patients are characterised as dangerous, unpredictable, untrustworthy, unstable, lazy, weak, worthless and/or helpless (Rabkin, 1974; Bhugra, 1989; Fabrega, 1990). Stigma is typically attached to diseases for which people are considered culpable. Psychiatric disorders are often attributed to a cognitive or moral failing and/or to heredity factors for which there is no treatment (Rabkin, 1974).

Fear appears to be a deep-seated reaction, but one that is regularly reinforced by selective and melodramatic reports in the media of virtually 
every violent incident involving a psychiatric patient (Scheff, 1966; Angermeyer \& Mattschinger, 1996). Once reactivated, such attitudes may be slow to return to background levels (Angermeyer \& Mattschinger, 1996). The mass media have a prominent role in stereotyping with a potent variable interval intermittent reinforcement' schedule. The public are ignorant of the nature and frequency of violence in psychiatry because they are misinformed, as they have been for decades (Nunnally, 1961). 'Doctor bashing' may be an increasingly common sport in the media, but psychiatrists and psychiatric patients do receive relatively more criticism (further details available from the author upon request).

Psychiatric diagnosis and treatment probably attracts stigma in itself, given that social avoidance tends to increase with the amount of psychiatric contact a patient has had (Rabkin. 1974). However, a more medical, biological psychiatry may have helped to reduce stigma. It is possible, ironically, that community care may have increased real and perceived stigmatisation: but the reverse is equally plausible. Well conducted studies that could have informed these debates have not been carried out.

\section{What can be done?}

There is little doubt that stigmas can be created (e.g. drink-driving) and reduced (e.g. leprosy, syphilis, tuberculosis and cancer), but casual observation suggests that the former is a lot easier and quicker to bring about than the latter. Education is the most obvious means of attempting to increase knowledge, soften attitudes and influence behaviour. Two early studies in southeast England failed to make much of an impact on community levels of knowledge (Anonymous, 1968). In the US, extensive community educational programmes during the 1960 s appeared to increase the ability of the general population to identify various mental illnesses and to regard them as similar to physical illnesses (Rabkin, 1974). However, studies of these apparent effects were often contradictory, probably according to methodology (Brockman et al, 1979). and the public may have responded as they thought they should even if they were not actually convinced (Rabkin, 1974). Recent studies do, however, suggest that education is popular (Kay et al. 1997) and reasonably effective, at least in the short-term, in increasing knowledge in adults (Wolff et al, 1996) and in children (Rahman et al. 1998).

Whether such information alters attitudes and behaviour is far from clear. Medical students learn enough to pass psychiatry exams, but their attitudes change little, if at all (Buchanan \& Bhugra, 1992) and doctors remain generally dismissive of psychiatric patients (Buchanan \&
Bhugra, 1992). We must try to correct misconceptions that psychiatry is a vague subject. that psychiatrists are ineffectual and that the patients are particularly awkward, although this will be difficult given the prominence of such views in medics and medical schools (Sinclair. 1997). The selection and training of medics may make them particularly difficult 'nuts to crack' (Sinclair, 1997).

Individual beliefs, personality characteristics and situational circumstances are all important determinants of attitudes (Rabkin, 1974). Education will probably be most effective therefore if it is specific, accurate, honest and targeted at particular social groups. For example. teachers may need encouragement to recognise psychiatric disorders that can cause disruptive behaviour or scholastic difficulties; while employers and insurers need information from high quality treatment and prognosis studies. The general public probably require little convincing that schizophrenia or the more severe affective disorders are 'real', but need a greater appieciation that milder disorders are not feigned, imaginary or responsive to exhortations to "pull up your socks'. There is little point in saying that patients with psychoses need not be frightening. but much value in describing the likely reasons for frightening behaviour and how to deal with it (Lagos, 1977). Perhaps most importantly, given that the public believes psychiatric medication does more harm than good (e.g. Prlest et al, 1996), they need to be told about the extent to which various treatments can help in particular disorders.

Exposure to psychiatric patients may be better still. Increased contact with the mentally ill is generally associated with less critical attitudes (Penn et al, 1994), but very few intervention studies have been done. Rabkin (1974) suggested that direct contact seems to be beneficial in motivated interested students, but only works in the general population if they see patients in everyday roles. Wolff et al (1996) found that a reduction in the fear of the mentally ill depended upon direct contact with patients. If exposure to patients with psychiatric disorder desensitises public fear, as seems likely, then patients should be at the centre of any attempt to influence attitudes.

Media coverage of psychiatric issues appears to be a very important source of information and attitudes (Philo, 1996). Scheff (1966) thought that education was doomed to failure in the face of overwhelmingly negative images in the media. The only way that psychiatrists can directly influence reporting is by being proactive. It may be difficult to counter every negative with a positive, but newspapers should be encouraged to cover treatment advances and acknowledge that violence is extremely rare in psychiatric 
disorder, particularly when patients are properly treated. Forging links with particular journalists and supplying them with written information may help (Harrison, 1998). The Internet is an increasingly common source of medical knowledge and we must provide accessible, sensible alternatives to any misinformation.

Sartorius (1998), who is steering the World Psychiatric Association programme against the stigma of schizophrenia, suggests that psychiatrists should examine their own attitudes, be active advocates for those with psychiatric disorders, strive to improve the quality of life of patients, look out for discrimination in public services and learn from others on how to deal with stigmatisation. Above all, we must carefully assess the effects of any such measures, to identify what does and does not work. The College stigma campaign is a welcome initiative and will be evaluated (Cowan \& Hart, 1998). Thus far, all we know is that maintaining local relevance may be an important prerequisite for success (Kay et al, 1997: Harrison, 1998), particularly as regional newspaper coverage of psychiatry tends to be the most negative (Hart \& Phillipson, 1998).

\section{Conclusions}

Psychiatrists have to accept responsibility for the stigmatisation of psychiatric disorder - no-one else is going to. We need to know more about the attitudes to specific disorders and the influences on them. Are all psychiatric disorders really seen as simultaneously trivial, imaginary, lifelong and incurable? It could be argued that we should first focus on medics, but limited resources may be more profitably targeted at prospective employers and insurers. We must establish what works, and for whom. It is likely that we will need to involve patients and develop better links with their representatives if these initiatives are to succeed. In the meantime, every psychiatrist could and should be doing something at a local or regional level.

\section{References}

ANGERMEYER, M. C. \& MATSCHINGER, H. (1996) The effect of violent attacks by schizophrenic persons on the attitude of the public towards the mentally ill. Social Science and Medicine. 43. 1721-1728.

ANonymous (1968) Public attitudes to mental health education. British Medical Journal, i. 69-70.

Bhugra. D. (1989) Attitudes towards mental illness. Acta Psychiatrica Scandinavica, 80, 1-12.
BROCKMAN, J., D'ARCY, C. \& EDMONDS, L. (1979) Facts or artifacts? Changing public attitudes toward the mentally ill. Social Science and Medicine, 131. 673-682.

BuChANAN, A. \& BHUGRA. D. (1992) Attitude of the medical profession to psychiatry. Acta Psychiatrica Scandinavica, 86, 1-5.

COWAN, L. \& HART, D. (1998) Changing minds: every family in the land. Psychiatric Bulletin, 22, 593-554.

Fabrega. H. (1990) Psychlatric stigma in the classical and medieval period: a review of the literature. Comprehensive Psychiatry. 31. 289-306.

Goffman, E. (1963) Stigma. Englewood Cliffs. NJ: Prentice Hall.

HARRISON, T. (1998) Climbing Mount Everest: tackling the media at a regional level. Psychiatric Bulletin, 22, 111-112.

HART, D. \& PHILLIPSON. J. (1998) Public education: 12 years on. Psychiatric Bulletin. 22. 590-592.

HAYWARD, P. \& BRIGHT, J. A. (1997) Stigma and mental illness. Joumal of Mental Health, 6. 345-354.

KAY, R., MARTIN, B.. KELLY, D., et al (1997) Using the media during mental health week. Psychiatric Bulletin, 21. $451-453$

Lagos, J., Perimutter, K. \& SAeXinger, H. (1977) Fear of the mentally ill: empirical support for the common man's response. American Joumal of Psychiatry. 134. 11341137.

LAWRE, S. M., PARSONS, C., PATRICK. J., et al (1996) A controlled trial of general practitioners' attitudes to patients with schizophrenia. Health Bulletin. 54, 201-203.

-. MARTin, K.. McNeiL., G., et al (1998) General practitioners' attitudes to psychiatric and physical illness. Psychological Medicine, 28, 1463-1467.

NunNaldy, J. C. (1961) Popular Conceptions of Mental Health. New York: Holt, Rinehart \& Winston.

PEnN. D. L.. GuYnan. K.. Daily. T., et al (1994) Dispelling the stigma of schizophrenia: what sort of information is best? Schizophrenia Bulletin. 20, 567-577.

PHIL. G. (1996) Media and Mental Distress. London: Longman.

PRest, R. G., Vize, C., Roberts, A., et al (1996) Lay people's attitudes to treatment of depression: results of opinion poll for defeat depression campaign just before its launch. British Medical Journal, 313, 858-859.

RABKIN, J. (1974) Public attitudes toward mental illness: a review of the literature. Schizophrenia Bulletin. 10. 9-33.

RAHMan. A., MUbBashar, M. H.. GaTER, R., et al (1998) Randomised trial of school mental-health programme in rural Rawalpindi. Pakistan. Lancet, s52. 1022-1025.

READ, J. \& BAKER, S. (1996) Not Just Sticks and Stones. London: MIND.

Rosen J, G. (1968) Madness in Society. London: Routledge \& Kegan Paul.

SARTORJUS, N. (1998) Stigma: what can psychiatrists do about it? Lancet, 352, 1058-1059.

SCHEFF. T. J. (1966) On Being Mentally IL. London: Weidenfeld \& Nicolson.

SINCLAIR. S. (1997) Making Doctors. Oxford: Berg.

Wolff, G., Pathare, S., Craig, T., et al (1996) Public education for community care: a new approach. British Journal of Psychiatry, 168, 441-447.

Stephen M. Lawrie, Senior Clinical Research Fellow, Edinburgh University Department of Psychiatry, Royal Edinburgh Hospital, Edinburgh EH1O 5HF 